\title{
Síntese de proteína microbiana e concentração de ureia em novilhas leiteiras alimentadas com palma forrageira Opuntia
}

\author{
Microbial protein synthesis and concentration of urea in dairy \\ heifers fed diets with cactus forage Opuntia
}

\author{
Maria do Socorro Mercês Alves Aguiar ${ }^{*}$; Fabiano Ferreira da Siva²; \\ Sérgio Luiz Rodrigues Donato ${ }^{1}$; Alex Resende $\mathrm{Schio}^{3}$; Dicastro Dias de Souza \\ Murilo de Almeida Meneses ${ }^{4}$; Alex Aguiar Lédo ${ }^{1}$
}

\begin{abstract}
Resumo
Objetivou-se analisar a influência de teores crescentes de palma forrageira na dieta sobre o balanço de nitrogênio, as concentrações de ureia na urina e no plasma e a síntese de proteína microbiana em novilhas leiteiras $3 / 4$ Holandes-zebu confinadas. Utilizaram-se 24 novilhas com peso corporal médio inicial de $163,00 \pm 18 \mathrm{~kg}$, com 8 meses de idade e distribuídas em delineamento inteiramente casualizado, com quatro tratamentos e seis repetições. Utilizou-se silagem de sorgo, concentrado e teores crescentes de palma forrageira na dieta $\left(0,200,400\right.$ e $\left.600 \mathrm{~g} \mathrm{~kg}^{-1}\right)$. O nitrogênio ingerido, excretado nas fezes e urina, digerido e retido com adição da palma forrageira na dieta apresentaram efeito linear decrescente. $\mathrm{O}$ balanço de nitrogênio foi influenciado pela inclusão de palma forrageira na dieta das novilhas leiteiras através dos valores observados para o nitrogênio digerido e retido, o que pode estar relacionado aos efeitos similares encontrados para o consumo de nitrogênio e nas excreções de nitrogênio nas fezes e na urina. $\mathrm{O}$ nitrogênio digerido em porcentagem do ingerido e o nitrogênio retido em porcentagem do ingerido e digerido não apresentaram diferença com a inclusão de palma na dieta. A concentração de nitrogênio ureico na urina das novilhas apresentou efeito quadrático com ponto de máxima excreção no nível de 275,80 $\mathrm{g} \mathrm{kg}^{-1} \mathrm{de}$ palma forrageira na dieta. Em consequência, a excreção de nitrogênio ureico e ureia na urina apresentaram efeito semelhante com pontos de máxima excreção nos níveis de 293,75 e 319,00 $\mathrm{g} \mathrm{kg}^{-1}$ de palma forrageira na dieta. A concentração de nitrogênio ureico no plasma não apresentou diferença, com valor médio de $13,19 \mathrm{mg} \mathrm{dL}^{-1}$. Síntese de nitrogênio e proteína bruta microbiana ajustou ao modelo quadrático. A eficiência microbiana não foi influenciada pela inclusão da palma forrageira em substituição a silagem de sorgo e concentrado. As novilhas apresentaram volume urinário semelhante para os tratamentos, com valor médio de 5,90 litros de urina por dia, comprovando que a excreção de creatinina na urina não foi afetada pelos teores de palma forrageira nas dietas.
\end{abstract}

Palavras-chave: Balanço de nitrogênio, eficiência, purina, volume urinário

\footnotetext{
Abstract

The objective was to analyze the influence of increasing levels of forage cactus Opuntia in the diet on the nitrogen balance, the concentrations of urea in urine and plasma and microbial protein synthesis in dairy

${ }^{1}$ Profs. e Pesquisadores do Instituto Federal de Educação Ciência e Tecnologia Baiano, IFBaiano, Guanambi, BA. E-mail: socorromerces@yahoo.com.br; sergio.donato@guanambi.ifbaiano.edu.br; alex.ledo@guanambi.ifbaiano.edu.br.

2 Prof. e Pesquisador da Universidade do Sudoeste da Bahia, UESB, Itapetinga, BA. E-mail: ffsilva@pq.cnpq.br

3 Dr. em Zootecnia e Pesquisador da UESB, Itapetinga, BA. E-mail. resendezoo@hotmail.com.

${ }^{4}$ Discentes do Curso de Doutorado Produção de Ruminantes, UESB, Itapetinga, BA. E-mail: dico111_3@hotmail.com; dddmeneses@msn.com

* Autor para correspondência
} 
heifers $3 / 4$ Holstein-zebu confined. twenty four heifers were used with initial body weight of $163.00 \pm 18$ $\mathrm{kg}$, with 8 months old and distributed in a completely randomized design with four treatments and six replications. It was used sorghum silage, concentrate and increasing levels of forage cactus Opuntia in the diet $(0,200,400$ and $600 \mathrm{~g} \mathrm{~kg}-1)$. The nitrogen intake, feces and urine, digested and retained with the addition of forage cactus in the diet showed decreasing linear effect. Nitrogen balance was influenced by the inclusion of forage cactus in the diet of dairy heifers through the values observed for the digested and retained nitrogen, which can be related to similar effects found for the consumption of nitrogen and the nitrogen excretion in feces and urine. Nitrogen digested percentage of intake and nitrogen retention as a percentage of ingested and digested showed no difference with the inclusion of forage cactus in the diet. The concentration of urea nitrogen in the urine of heifers had a quadratic effect point of maximum excretion level of $275.80 \mathrm{~g} \mathrm{~kg}^{-1}$ of forage cactus in the diet. Consequently, the excretion of urea nitrogen and urea excretion showed similar effect with maximum points excretion levels of 293.75 and $319.00 \mathrm{~g} \mathrm{~kg} \mathrm{k}^{-1}$ of forage in the diet. The concentration of ureic nitrogen in plasma showed no difference, with an average value of $13.19 \mathrm{mg} \mathrm{dL}^{-1}$. Synthesis of nitrogen and microbial crude protein adjusted to the quadratic model. The microbial efficiency was not influenced by the inclusion of forage cactus in replacement of sorghum silage and concentrate. The urine volume similar to the treatments, with an average of 5.90 liters of urine per day, proving that the creatinine excretion in urine was not influenced by the levels of forage cactus in the diet.

Key words: Efficiency, nitrogen balance, purine, urine volume

\section{Introdução}

O objetivo dos estudos de nutrição de ruminantes é maximizar a síntese de proteína microbiana, em virtude de seu excelente balanceamento de aminoácidos (VALADARES FILHO; VALADARES, 2001). Porém, observa-se em geral negligência quanto ao manejo e à alimentação de novilhas, com fornecimento de suplemento dietético incompatível com a elevada exigência desses animais para crescimento, o que pode comprometer o ganho de peso e favorecer o aumento na idade ao primeiro parto (CHIZZOTTI et al., 2006).

O elevado custo com alimentação destes animais, ainda não compensado pela produção de leite, dificulta o suprimento de uma dieta adequada à expressão do potencial produtivo, e por isso é a principal causa dessa baixa produtividade.

A avaliação do balanço de nitrogênio no animal e da concentração de ureia no soro e na urina permite a obtenção de informações a respeito da nutrição proteica dos ruminantes, o que pode ser importante para evitar prejuízos produtivos, reprodutivos e ambientais, decorrentes do fornecimento de quantidades excessivas de proteína ou da inadequada sincronia energia- proteína no rúmen (PESSOA et al., 2009).

O fornecimento de aminoácidos a partir da proteína microbiana é fundamental para o metabolismo proteico dos ruminantes, uma vez que a maior parte dos aminoácidos absorvidos no intestino delgado é proveniente da proteína microbiana. A eficiência de produção microbiana e o fluxo microbiano são fatores determinantes da quantidade de proteína microbiana que alcança o intestino delgado. De acordo com o NRC (2001), as proteínas sintetizadas pelos microrganismos ruminais possuem excelente perfil aminoacídico e composição pouco variável. Dessa forma, o estudo dos mecanismos de síntese proteica microbiana e dos fatores relacionados é de grande importância.

Existe uma correlação positiva entre a ingestão de N e a concentração de ureia no soro (PRESTON; SCHNAKENBERG; PFANDER, 1965). De acordo com Broderick e Clayton (1997), a concentração elevada de ureia plasmática está relacionada à utilização ineficiente da proteína bruta da dieta. A quantidade de ureia sintetizada no fígado é proporcional à concentração de amônia produzida no rúmen e sua concentração sanguínea está diretamente relacionada ao aporte proteico e à relação energia:proteína dietética (HARMEYER; 
MARTENS, 1980). O teor de nitrogênio uréico no soro (NUS) é utilizado para obtenção de informações adicionais sobre a nutrição proteica de ruminantes, por meio da resposta metabólica à determinada dieta.

Vários estudos confirmam a relação entre produção de proteína microbiana e excreção de derivados de purina na urina (RENNÓ et al., 2000; VAGNONI et al., 1997). A excreção de derivados de purina na urina consiste em um método simples e não-invasivo para estimativa da produção de proteína microbiana no rúmen. Nessa técnica, assume-se que os ácidos nucléicos presentes no duodeno são de origem predominantemente microbiana e que, após digestão intestinal dos nucleotídeos purínicos, as purinas absorvidas são catabolizadas e recuperadas proporcionalmente na urina como derivados de purinas.

Segundo Chen e Gomes (1992), a alantoína e o ácido úrico são os principais derivados de purina presentes na urina de bovinos, pois a alta atividade da enzima xantina oxidase no sangue e nos tecidos converte xantina e hipoxantina em ácido úrico antes da excreção, sendo a excreção de xantina e hipoxantina considerada irrisória em bovinos.

Segundo Valadares et al. (1997), é possível simplificar a coleta de urina utilizando-se a excreção de creatinina na urina como indicador da produção urinária, uma vez que essa excreção é relativamente constante em função do peso corporal pelo fato de ser pouco ou não afetada por fatores dietéticos (CHEN et al., 1995; RENNÓ et al., 2000).

Assim, se coletada uma única amostra de urina, denominada amostra spot, e determinada a concentração de creatinina, a excreção de compostos urinários como a ureia e os derivados de purinas (DP) pode ser estimada, facilitando a obtenção de dados experimentais e possibilitando a utilização dessa técnica a campo.

Como alternativa para manter os ganhos de peso ideais em novilhas leiteiras com menor custo, sugere-se o uso de alimentos alternativos, como a palma forrageira em substituição a silagem de sorgo e o concentrado.

Objetivou-se avaliar a influência de teores crescentes de palma forrageira na dieta sobre o balanço de compostos nitrogenados, as concentrações de ureia na urina e no plasma e a síntese de proteína microbiana em novilhas leiteiras confinadas.

\section{Material e Métodos}

O presente trabalho foi conduzido no setor de bovinos do Instituto Federal de Educação, Ciência e Tecnologia Baiano, Campus Guanambi, Município de Guanambi, Estado da Bahia. O referido local apresenta latitude de $14^{\circ} 17^{\prime} 27^{\prime \prime} \mathrm{S}$, longitude de 42 46'53" W, altitude de $537 \mathrm{~m}$, precipitação média anual de $680 \mathrm{~mm}$ e temperatura média anual de $26{ }^{\circ} \mathrm{C}$.

Foram utilizadas 24 novilhas mestiças leiteiras (3/4 holandês-zebu), com peso corporal médio de $163,00 \pm 18 \mathrm{~kg}$, com idade de 8 meses, identificadas com brincos numerados. Os animais, após o controle de ecto e endoparasitos, passaram por um período de 14 dias de adaptação ao manejo experimental e às instalações. $O$ período de coleta de dados foi de 84 dias. Os animais foram alojados em baias individuais cobertas, com piso de concreto, com área de $3,5 \mathrm{~m}^{2}$. As baias foram providas de cocho individual para alimentação e controle de consumo e um bebedouro para duas baias.

O delineamento experimental utilizado foi o inteiramente casualizado, com quatro dietas e seis repetições. Após análise bromatológica da silagem de sorgo e da palma forrageira (Tabela 1), as dietas foram estimadas com o objetivo de serem isonitrogenadas e isoenergéticas.

Utilizou-se silagem de sorgo como volumoso, e como concentrado milho, farelo de soja, ureia, sal de recria, calcário, fosfato bicálcio e teores crescentes de palma forrageira em substituição ao volumoso e o concentrado $\left(0 ; 200 ; 400\right.$ e $\left.600 \mathrm{~g} \mathrm{~kg}^{-1}\right)$. 
Tabela 1. Composição químico-bromatológica $\left(\mathrm{g} \mathrm{kg}^{-1}\right)$ da silagem de sorgo e da palma forrageira.

\begin{tabular}{|c|c|c|}
\hline Componentes & Silagem de sorgo & Palma forrageira \\
\hline Matéria Seca ( $\mathrm{g} \mathrm{kg}^{-1}$ de matéria natural) & 325,60 & 92,80 \\
\hline Proteína $\operatorname{Bruta}^{1}\left(\mathrm{~g} \mathrm{~kg}^{-1}\right)$ & 110,50 & 101,60 \\
\hline Fibra em Detergente Neutro corrigida para cinzas e proteina ${ }^{1}\left(\mathrm{~g} \mathrm{~kg}^{-1}\right)$ & 580,40 & 314,70 \\
\hline Fibra em Detergente Àcido $\left(\mathrm{g} \mathrm{kg}^{-1}\right)$ & 416,30 & 222,70 \\
\hline Extrato Etéreo $\left(\mathrm{g} \mathrm{kg}^{-1}\right)$ & 17,10 & 13,50 \\
\hline Material Mineral $^{1}\left(\mathrm{~g} \mathrm{~kg}^{-1}\right)$ & 88,30 & 151,30 \\
\hline $\operatorname{Lignina}^{1}\left(\mathrm{~g} \mathrm{~kg}^{-1}\right)$ & 75,10 & 32,60 \\
\hline Fibra Detergente Neutro indigestível ${ }^{1}\left(\mathrm{~g} \mathrm{~kg}^{-1}\right)$ & 198,60 & 114,50 \\
\hline Nitrogênio Insolúvel em Detergente Neutro ${ }^{2}\left(\mathrm{~g} \mathrm{~kg}^{-1}\right)$ & 221,10 & 226,70 \\
\hline Carboidratos Não Fibrosos ${ }^{1}\left(\mathrm{~g} \mathrm{~kg}^{-1}\right)$ & 203,40 & 418,70 \\
\hline Nutrientes Digestíveis Totais ${ }^{1}\left(\mathrm{~g} \mathrm{~kg}^{-1}\right)$ & 70,61 & 58,93 \\
\hline
\end{tabular}

${ }^{1} \mathrm{~g} \mathrm{~kg}^{-1}$ na matéria seca, ${ }^{2} \mathrm{~g} \mathrm{~kg}^{-1}$ do nitrogênio total.

Fonte: Elaboração dos autores.

Para a preparação da silagem foi realizada a colheita do sorgo forrageiro [Sorghum bicolor (L.) Moench] aos 100 dias de idade, com os grãos no ponto pastoso-farináceo. Foi utilizada ensiladeira e a planta foi fragmentada em partículas de 0,5 a $2,0 \mathrm{~cm}$, com a finalidade de facilitar a compactação, o processo digestivo e o desempenho dos animais. Posteriormente, o material fragmentado foi armazenado em silo tipo superfície e compactado com trator. A vedação ocorreu após o término do enchimento.

Ao final de cento e vinte dias o silo foi aberto, e a silagem apresentava coloração normal e cheiro agradável.

As análises das amostras da silagem de sorgo, da palma forrageira, concentrados, das sobras e das fezes foram realizadas no Laboratório de Forragicultura e Pastagens da Universidade Estadual do Sudoeste da Bahia (UESB), Campus Itapetinga, de acordo as metodologias descritas por Silva e Queiroz (2009): matéria seca (MS), proteína bruta (PB), fibra em detergente ácido (FDA), lignina (LIG), matéria mineral (MM), extrato etéreo (EE), nitrogênio insolúvel em detergente ácido (NIDA), nitrogênio insolúvel em detergente neutro (NIDN) e carboidratos insolúveis em detergente neutro (CIDN).
A fibra em detergente neutro, isenta de cinzas e proteínas (FDNcp), foi calculada segundo Mertens (2002) e Licitra, Hernandez e Van Soest (1996).

Todas as amostras de fibra em detergente neutro (FDN) foram corrigidas para cinza e proteína; o resíduo da digestão em detergente neutro foi incinerado em mufla a $600^{\circ} \mathrm{C}$ por 2 horas e a correção para proteína foi realizada utilizando a proteína insolúvel em detergente neutro (PIDN). $\mathrm{Na}$ determinação de PIDN e proteína insolúvel em detergente ácido (PIDA), foi empregada a metodologia descrita por Licitra, Hernandez e Van Soest (1996).

Nas análises de fibra em detergente neutro (FDN) e fibra em detergente ácido (FDA) dos concentrados, silagem de sorgo, palma forrageira e sobras, foram adicionadas amilase termoestável para minimizar interferência do amido (SILVA; QUEIROZ, 2009).

Os teores de carboidratos não fibrosos foram corrigidos para cinza e proteína (CNFcp) e foram calculados como proposto por Hall (2003), em que:

$$
\mathrm{CNF}=(100-\% \mathrm{FDNcp}-\% \mathrm{~PB}-\% \mathrm{EE}-\% \text { cinza }) \text {. }
$$

Em que: FDNcp é a fibra em detergente neutro corrigida para cinza e proteína, PB é proteína bruta e EE é extrato etéreo. 
As dietas foram distribuídos às novilhas (Tabela 2), sendo as dietas compostas de concentrado, silagem de sorgo e palma forrageira em substituição a silagem de sorgo e concentrado. As dietas foram calculadas para conterem nutrientes suficientes a fim de proporcionarem ganho de peso corporal (PC) de
$0,80 \mathrm{~kg} \mathrm{dia}^{-1}$, de acordo com o NRC (2001) utilizando dados das análises bromatológicas dos alimentos previamente realizadas no início do período de adaptação. As composições químicas resultantes das combinações percentuais dos alimentos para cada dieta experimental constam na Tabela 2.

Tabela 2. Proporções de ingredientes ( $\mathrm{g} \mathrm{kg}$ de matéria seca) e composição nutricional das dietas experimentais, utilizada em novilhas 3/4 holandês-zebu em função dos teores de palma forrageira na dieta

\begin{tabular}{|c|c|c|c|c|}
\hline \multirow{2}{*}{ Ingredientes $\left(\mathrm{g} \mathrm{kg}^{-1}\right)$} & \multicolumn{4}{|c|}{ Dietas } \\
\hline & $\mathbf{0}$ & 200 & 400 & 600 \\
\hline Silagem de sorgo & 647,00 & 555,60 & 444,40 & 342,00 \\
\hline Palma forrageira & 0,00 & 185,20 & 388,90 & 591,50 \\
\hline Milho & 236,60 & 157,40 & 79,60 & 0,00 \\
\hline Farelo soja & 96,10 & 81,50 & 66,70 & 46,20 \\
\hline Ureia & 7,40 & 7,40 & 7,40 & 7,40 \\
\hline Sal recria & 5,50 & 5,60 & 5,60 & 5,50 \\
\hline Calcário & 5,50 & 5,60 & 5,60 & 5,50 \\
\hline Fosfato bicálcio & 1,80 & 1,90 & 1,90 & 1,80 \\
\hline \multicolumn{5}{|l|}{ Composição Nutricional } \\
\hline Matéria Seca $(\mathrm{g} \mathrm{kg})$ & 424,10 & 227,10 & 157,50 & 123,80 \\
\hline Proteína Buta $(\mathrm{g} \mathrm{kg})^{1}$ & 154,30 & 161,70 & 154,40 & 131,40 \\
\hline Fibra em Detergente Neutro $\mathrm{cp}\left(\mathrm{g} \mathrm{kg}^{-1}\right)^{1 ; 3}$ & 422,00 & 420,20 & 389,80 & 375,80 \\
\hline Fibra em Detergente Acido $^{1}$ & 278,10 & 277,50 & 271,00 & 267,80 \\
\hline Extrato Etéreo $\left(\mathrm{g} \mathrm{kg}^{-1}\right)^{1}$ & 16,20 & 15,30 & 14,90 & 14,50 \\
\hline Material Mineral $\left(\mathrm{g} \mathrm{kg}^{-1}\right)^{1}$ & 79,00 & 101,60 & 132,40 & 139,60 \\
\hline Lignina $\left(\mathrm{g} \mathrm{kg}^{-1}\right)^{1}$ & 52,30 & 47,40 & 44,80 & 42,90 \\
\hline Nitrogênio Insolúvel em Detergente Neutro $\left(\mathrm{g} \mathrm{kg}^{-1}\right)^{2}$ & 207,40 & 216,40 & 217,80 & 220,60 \\
\hline Carboidratos Não Fibrosos $\left(\mathrm{g} \mathrm{kg}^{-1}\right)^{1}$ & 157,20 & 217,40 & 276,60 & 335,50 \\
\hline Nutrientes Digestíveis Totais $\left(\mathrm{g} \mathrm{kg}^{-1}\right)^{1}$ & 650,00 & 600,00 & 573,20 & 503,30 \\
\hline
\end{tabular}

${ }^{1} \mathrm{~g}$ em kg da matéria seca, ${ }^{2} \mathrm{~g}$ em kg do nitrogênio total; ${ }^{3}$ fibra em detergente neutro corrigida para cinzas e proteína.

Fonte: Elaboração dos autores.

As rações foram oferecidas duas vezes ao dia (às $07 \mathrm{~h} 00$ e às 17h00) na forma de mistura completa, e a água suprida permanentemente à vontade.

Durante 84 dias, divididos em três períodos de 28 dias, coletaram-se amostras das rações ofertadas, das sobras, foram mensurados o peso corporal, altura à cernelha e perímetro torácico e na última semana do período do experimental, foram realizadas coleta de urina para amostra em spot, aproximadamente 4 horas após a alimentação, durante micção espontânea.

Do total da urina coletada, após homogeneização e filtragem em gaze, foram obtidas alíquotas de 10 $\mathrm{mL}$, diluídas em $40 \mathrm{~mL}$ de ácido sulfúrico $0,036 \mathrm{~N}$, conforme descrito por Valadares et al. (1999). Estas alíquotas foram acondicionadas em recipientes plásticos identificados e congeladas, para posteriores 
análises e quantificação da ureia, nitrogênio total, creatinina, ácido úrico e alantoína.

Amostras de sangue foram coletadas no primeiro e último dia dos períodos experimentais, via punção da veia jugular, utilizando-se tubos de ensaio (Vacutainer $^{T M}$ ) de $5 \mathrm{~mL}$ com EDTA (anticoagulante). Imediatamente, procedeu-se à centrifugação a 5.000 rpm por 15 minutos e, posteriormente, retiraram-se amostras de plasma, que foram acondicionadas em eppendorf e armazenadas a $-15^{\circ} \mathrm{C}$ para posteriores análises de ureia.

As concentrações de ureia, creatinina e ácido úrico na urina e de ureia no plasma foram estimadas utilizando-se kits comerciais (Bioclin). A conversão dos valores de ureia em nitrogênio ureico foi realizada pela multiplicação dos valores obtidos pelo fator 0,4667 .

Os teores urinários de alantoína e ácido úrico foram estimados por métodos colorimétricos, conforme especificações de Chen e Gomes (1992), e o teor de nitrogênio total estimado pelo método de Kjeldhal (SILVA; QUEIROZ, 2009).

$\mathrm{O}$ balanço dos compostos nitrogenados (N retido, $\mathrm{g} \mathrm{dia}^{-1}$ ) foi calculado como:

\section{$\mathrm{N}$ retido $(\mathrm{g})=\{\mathrm{N}$ ingerido $(\mathrm{g})-\mathrm{N}$ fezes $(\mathrm{g})-\mathrm{N}$ urina $(\mathrm{g})\}$}

em que: $\mathrm{N}$ retido $=$ nitrogênio retido no organismo do animal; $\mathrm{N}$ ingerido = nitrogênio ingerido pelo animal; $\mathrm{N}$ fezes $=$ nitrogênio excretado nas fezes e $\mathrm{N}$ urina $=$ nitrogênio excretados na urina.

A excreção de creatinina ( $\left.\mathrm{mg} \mathrm{kg}^{-1} \mathrm{PC}\right)$ utilizada para estimar o volume urinário por intermédio das amostras spots foi obtida para cada animal, segundo a equação descrita por Chizzotti et al. (2004):

$$
\mathrm{EC}=\{32,27-0,01093 \times \mathrm{PC}\}
$$

em que: $\mathrm{EC}=$ excreção diária de creatinina (mg $\left.\mathrm{kg}^{-1} \mathrm{PC}\right)$; e $\mathrm{PC}=$ peso corporal $(\mathrm{kg})$.

Uma vez que, em animais em crescimento, a porcentagem de tecido muscular varia de acordo com o peso corporal e, consequentemente, a excreção de creatinina ( $\mathrm{mg} \mathrm{kg}^{-1}$ de $\mathrm{PV}$ ) pode ser alterada.

O volume urinário total diário foi estimado dividindo-se as excreções urinárias diárias de creatinina pelos valores observados de concentração de creatinina na urina (VALADARES FILHO; VALADARES, 2001).

A excreção de purinas totais (PT) foi estimada pela soma das quantidades de alantoína e ácido úrico excretadas na urina e a quantidade de purinas microbianas absorvidas $\left(\mathrm{mmol}^{-1 a^{-1}}\right)$, pela excreção de purinas totais $\left(\mathrm{mmol} \operatorname{dia}^{-1}\right)$, por meio da equação proposta por Verbic et al. (1990):

$$
\mathrm{PA}=\left\{\frac{\mathrm{PT}-0,385 \times \mathrm{PC}^{0,75}}{0,85}\right\}
$$

em que: $\mathrm{PA}=$ purinas absorvidas $\left(\mathrm{mmol} \mathrm{dia}^{-1}\right)$; e $\mathrm{PT}=$ purinas totais $\left(\mathrm{mmol} \mathrm{dia}^{-1}\right) ; 0,85=$ recuperação de purinas absorvidas como derivados de purina na urina; e 0,385 = excreção endógena de derivados de purina na urina ( $\mathrm{mmol}$ ) por unidade de tamanho metabólico $\left(\mathrm{PC}^{0,75}\right)$.

Para estimativa da produção de proteína microbiana, foram utilizadas as bases purinas (mmol dia $^{-1}$ ) como indicador microbiano, cuja quantificação foi realizada de acordo com técnica de Chen e Gomes (1992):

$$
\mathrm{NM}(\mathrm{g} / \mathrm{dia})=\left\{\frac{70 \times \mathrm{PA}}{0,83 \times 0,116 \times 1000}\right\}
$$

Assumindo-se o valor de 70 para o conteúdo de nitrogênio nas purinas $\left(\mathrm{mg} \mathrm{mmol}{ }^{-1}\right) ; 0,83$ para a digestibilidade intestinal das purinas microbianas e 0,116 para a relação $\mathrm{N}_{\text {PURINA }}: \mathrm{N}_{\text {TOTAL }}$ nas bactérias. 
A eficiência de síntese microbiana (ESPBmic) foi calculada da seguinte forma:

$\mathrm{ESPBmic}=[(0,629 \times \mathrm{PA}) \times 6,25)] /$ CNDT.

Em que: $\mathrm{PA}=$ purinas absorvidas $\left(\mathrm{mmol} \mathrm{dia}^{-1}\right)$; CNDT $=$ consumo de nutrientes digestíveis totais; 0,629 representa a purina absorvida sem considerar a contribuição da fração endógena.

Os resultados foram interpretados estatisticamente por meio de análises de variância e de regressão com auxílio do SAEG 9.0 (2005). Os critérios utilizados para escolha dos modelos de regressão consideraram a adequação do modelo aos fenômenos estudados, os valores dos coeficientes de determinação ajustados e a significância dos parâmetros da regressão pelo teste t.

\section{Resultados e Discussão}

O nitrogênio ingerido, excretado nas fezes, digerido, excretado na urina e retido (Tabela 3 ) expressaram efeito linear decrescente $(\mathrm{P}<0,05)$, reduzindo 0,$16 ; 0,06 ; 0,10 ; 0,01$ e $0,09 \mathrm{~g}$ dia $^{-}$ 1 , respectivamente, para cada unidade de palma inclusa na dieta das novilhas.

A redução na quantidade de nitrogênio ingerida está relacionada à diminuição de consumo de NDT e a similaridade dos teores de PB $\left(\mathrm{g} \mathrm{kg}^{-1}\right)$ das rações. Cruz et al. (2006) avaliaram vacas alimentadas com palma forrageira e silagem de sorgo como volumoso e concentrado contendo quatro níveis de ureia, encontraram maior ingestão de nitrogênio para as dietas que proporcionaram maior consumo de matéria seca.

Pessoa et al. (2009) observaram maior ingestão de nitrogênio pela maior concentração de proteína bruta na dieta de novilhas alimentadas com palma forrageira e bagaço de cana como volumoso e concentrado $(0,5 \%$ do peso corporal) contendo farelo de soja ou farelo de algodão, comparada aos concentrados contendo farelo de trigo e caroço de algodão. $\mathrm{O}$ ocorrido constitui reflexo dos maiores teores de nitrogênio nesses suplementos.

Aumento no consumo de nitrogênio devido ao aumento do consumo de matéria seca ou maior teor de proteína bruta da dieta tem sido observado em vários estudos (CAVALCANTE et al., 2006; CRUZ et al., 2006; ÍTAVO et al., 2002; RENNÓ et al., 2008; VALADARES et al., 1997).

A menor excreção de nitrogênio $(\mathrm{P}<0,05)$ nas fezes e urina à medida que foi incluída palma forrageira à dieta (em substituição ao volumoso e concentrado) está relacionada à magnitude da ingestão de nitrogênio. Segundo Van Soest (1994), a excreção de nitrogênio na urina é maior quando a concentração de proteína bruta na dieta e a ingestão de nitrogênio pelo animal aumentam. Valadares et al. (1997) também observaram maior excreção de nitrogênio na urina de novilhos zebuínos em função do aumento da ingestão de nitrogênio da dieta.

Portanto, o balanço de nitrogênio foi influenciado $(\mathrm{P}<0,05)$ pela inclusão de palma na dieta das novilhas através dos valores observados para o nitrogênio digerido e retido, o que pode estar relacionado aos efeitos similares encontrados para o consumo de nitrogênio e nas excreções de nitrogênio nas fezes e na urina. Contudo, o nitrogênio digerido em porcentagem do ingerido e o nitrogênio retido em porcentagem do ingerido e digerido não foram influenciados $(\mathrm{P}>0,05)$ pela inclusão de palma na dieta, sendo observado valores de 66,29; 62,53 e 94,28\%, respectivamente. 


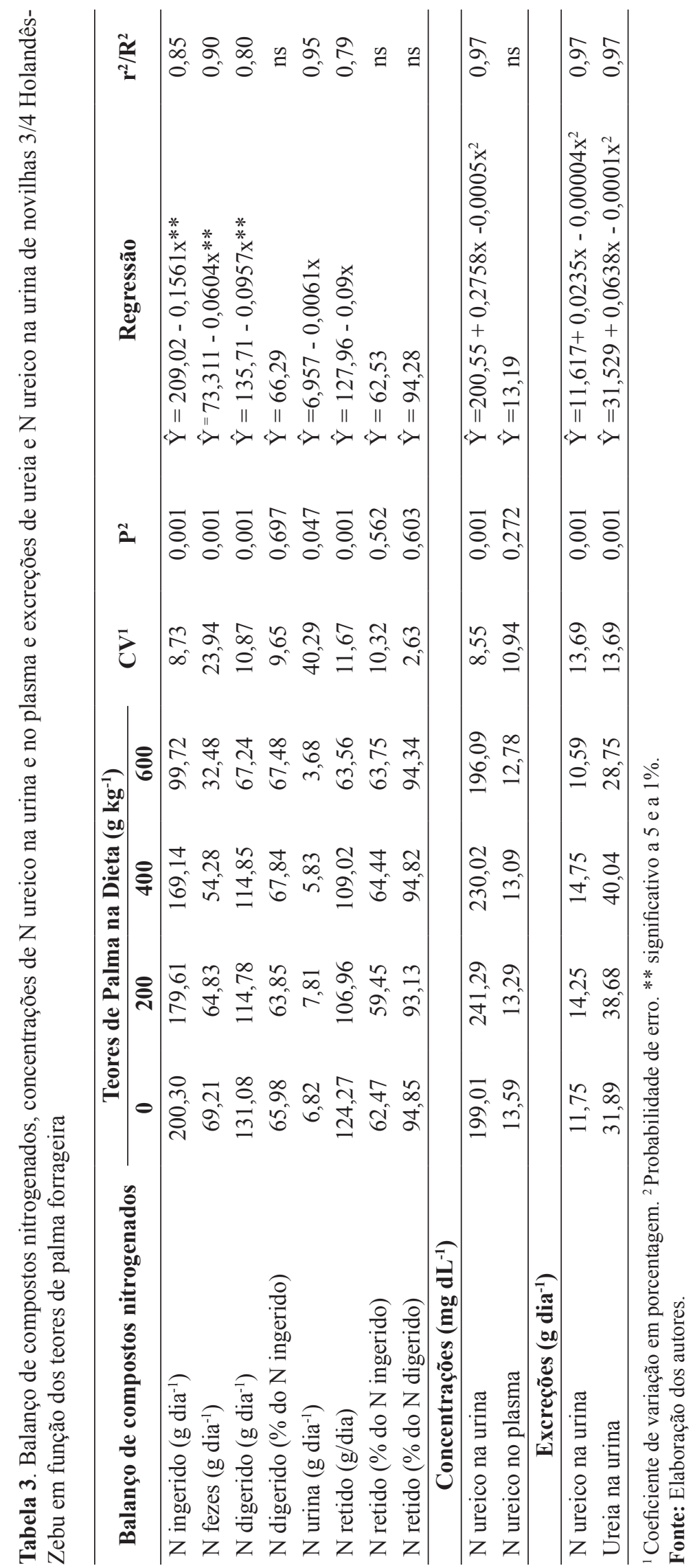


A concentração de nitrogênio ureico na urina das novilhas apresentou efeito quadrático $(\mathrm{P}<0,05)$ com ponto de máxima excreção correspondente ao teor de 275,80 $\mathrm{g} \mathrm{kg}^{-1}$ de palma inclusa na dieta. Em consequência, a excreção de nitrogênio ureico e ureia na urina apresentaram efeito semelhante com pontos de máxima excreção correspondente aos teores de 293,75 e $319,00 \mathrm{~g} \mathrm{~kg}^{-1}$ de palma inclusa na dieta. A concentração de nitrogênio ureico no plasma não apresentou diferença $(\mathrm{P}>0,05)$, com valor médio de $13,19 \mathrm{mg} \mathrm{dL}^{-1}$.

Quanto maior o teor proteico da dieta, maior a produção de amônia e maiores as concentrações de ureia no soro e as perdas nitrogenadas pela urina (PESSOA et al., 2009). Nesta pesquisa as dietas contendo aproximadamente valores entre 275 e $320 \mathrm{~g} \mathrm{~kg}^{-1}$ de palma resultaram em maiores concentrações e excreção de ureia na urina, sendo justificado pelo maior consumo de MS, maior teor de ureia nesta dieta comparado as dietas contendo maiores inclusões de palma e pelo alto teor de nitrogênio não proteico da palma forrageira, 1,80\% da matéria seca (VALADARES FILHO et al., 2008). A excreção de ureia representa elevado custo biológico e desvio de energia para manutenção das concentrações corporais de nitrogênio em níveis não tóxicos aos animais. A conversão da amônia em ureia custa ao animal $12 \mathrm{kcal} \mathrm{g}^{-1}$ de nitrogênio (VAN SOEST, 1994).
O comportamento observado para concentração de nitrogênio ureico no plasma está de acordo com os níveis de proteína bruta nas dietas. Os teores de nitrogênio ureico no plasma têm sido utilizados para obtenção de informações sobre o perfil da nutrição proteica de ruminantes, envolvendo suas respostas metabólicas a determinadas dietas (CHIZZOTTI et al., 2006). Nesse sentido, a concentração sérica de ureia está relacionada à utilização da proteína bruta da dieta e maiores concentrações podem caracterizar ineficiência na utilização da proteína e maiores perdas de energia.

Rennó et al. (2000) observaram aumento linear na concentração plasmática de ureia com o incremento dos níveis de proteína bruta na dieta. Valadares et al. (1997), em pesquisa com novilhos alimentados com dietas contendo 7,0; 9,5;12,0 e $14,5 \%$ de proteína bruta, observaram influência do teor proteico da dieta sobre os níveis de nitrogênio ureico no plasma, que foram de 8,$1 ; 9,1 ; 15,7$ e 19,5 $\mathrm{mg} \mathrm{dL} \mathrm{dL}^{-1}$, respectivamente. Butler, Cherney e Elrod (1995) sugeriram que, quando o nitrogênio ureico no soro excede 19-20 mg dL-1, a taxa de concepção pode ser reduzida em aproximadamente $20,0 \%$.

$\mathrm{O}$ volume urinário foi semelhante $(\mathrm{P}>0,05)$ para os teores de palma de 0, 200, 400 e $600 \mathrm{~g} \mathrm{~kg}^{-1}$ incluídos na dieta (Tabela 4), com valor médio de 5,90 litros de urina por dia, comprovando que a excreção de creatinina na urina não foi afetada pelos níveis de palma forrageira nas dietas. 


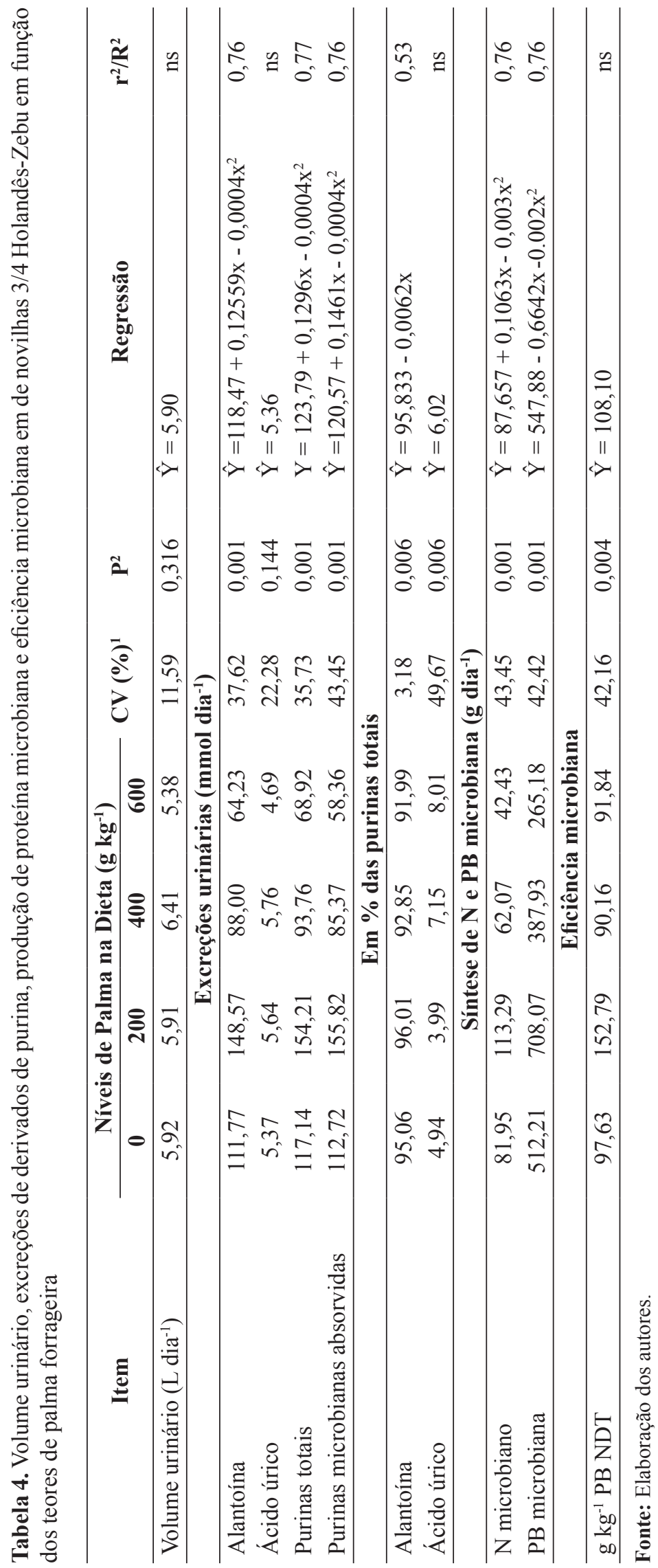


Segundo o NRC (2001), as perdas de água pela novilha ocorrem principalmente pelas perdas fecais e urinárias. As perdas pelas fezes são similares, próximas a $35 \%$ da ingestão total de água, enquanto a perda pela urina é próxima à metade das perdas fecais e varia de 15 a 21\%. A semelhança do volume urinário, observado nesta pesquisa, apesar das dietas que continham palma forrageira, ter maior teor de água, pode estar relacionada a sua maior excreção pelas fezes que apresentaram concentração de 90,16; 91,83; 92,86 e 93,79 de MS para os teores de palma forrageira de 0,200, 400 e $600 \mathrm{~g} / \mathrm{kg}$ incluídos na dieta nestes tratamentos.

As excreções urinárias de alantoína, purinas totais e purinas microbianas absorvidas, foram influenciadas pela inclusão de palma forrageira na dieta das novilhas, de forma quadrática $(\mathrm{P}<0,05)$, o modelo ajustado estima a maior excreção de 165,87 ; 167,48 e $132,76 \mathrm{mmol} \mathrm{dia}^{-1}$, respectivamente, com o teor máximo de 128,89; 134,64 e 132,76 $\mathrm{g} \mathrm{kg}^{-1}$ de palma forrageira adicionada a dieta. Consequentemente, a síntese de nitrogênio e proteína bruta microbiana, também verificaram efeito quadrático $(\mathrm{P}<0,05)$, o modelo ajustado estima 96,52 e 603,26 $\mathrm{g} \mathrm{dia}^{-1}$ de nitrogênio e proteína microbiana, com o teor de $166,77 \mathrm{~g} \mathrm{~kg}^{-1}$ de palma forrageira na dieta.

Segundo Pessoa et al. (2009) entre os aspectos de maior importância em dietas à base de palma forrageira, destaca-se o equilíbrio entre o suprimento de carboidratos fibrosos e não fibrosos. Em relação, ao decréscimo da síntese microbiana com inclusão de palma forrageira (com o teor acima de 166,77g $\mathrm{kg}^{-1}$ ), pode estar relacionada: ao menor consumo de NDT; pelo efeito físico devido ao alto teor de água; pelo perfil da fração fibrosa destas dietas, a qual diminui o estímulo à mastigação, contribuindo para menor produção de saliva e diluição do conteúdo ruminal, diminuindo a taxa de passagem do líquido e o escape de microrganismos. Segundo Valadares Filho et al. (2006), a taxa de passagem é um dos fatores que influenciam os padrões de fermentação ruminal e a síntese microbiana. De acordo com Nocek e Russell (1988), a eficiência do crescimento microbiano depende da partição da energia em mantença e crescimento e está inversamente relacionada ao tempo de permanência dos microrganismos no ambiente ruminal. Nesse sentido, quanto mais rápida a passagem de microrganismos, menor a utilização de energia para mantença e maior a eficiência de síntese microbiana. Segundo Chizzotti et al. (2007), a maior produção microbiana está de acordo com o consumo mais elevado, o qual disponibilizou maior quantidade de substratos fermentáveis e elevou a taxa de passagem aumentando o arraste de microrganismos do rúmen.

Não houve diferença $(\mathrm{P}>0,05)$ para excreção urinária de ácido úrico, apresentando valor médio de 5,36 $\mathrm{mmol} \mathrm{dia}^{-1}$. Esse valor foi próximo ao encontrado por Ferreira et al. (2009) de 6,00 mmol $\mathrm{dia}^{-1}$, que administraram dietas a base de palma forrageira para vacas holandesas. Magalhães et al. (2005) encontraram valor médio de 8,64 $\mathrm{mmol} \mathrm{dia}^{-1}$ para animais em crescimento.

A excreção urinária de alantoína em porcentagem das purinas totais expressou efeito linear decrescente $(\mathrm{P}<0,05)$, reduzindo $0,01 \%$ para cada unidade de palma forrageira inclusa à dieta. Já a excreção urinária de ácido úrico em porcentagem das purinas totais não foi influenciada $(\mathrm{P}>0,05)$ pela inclusão da palma forrageira na dieta, apresentando valor médio de $6,02 \%$ das purinas totais.

A inclusão da palma forrageira não afetou a eficiência microbiana $(\mathrm{P}>0,05)$, com valor médio de 108,10 $\mathrm{g} \mathrm{kg}^{-1}$ PB mic NDT (tabela 4). Considerando que boa parte do nitrogênio total das dietas foi oriundo da ureia, pode-se inferir que a alta concentração de carboidratos não fibrosos na palma forrageira em sincronia com o teor de ureia utilizado na dieta facilitou a incorporação do nitrogênio da ureia em proteína microbiana. Ferreira et al. (2009) pesquisaram diferentes volumosos, e encontraram valor médio de 100,79 $\mathrm{g} \mathrm{kg}^{-1}$ PBmic NDT quando utilizaram a silagem de sorgo associada a palma forrageira para vacas leiteiras, valor inferior ao 
presente estudo. O NRC (2001) propõe o valor de 130 $\mathrm{g} \mathrm{kg}^{-1}$ de PBmic NDT consumido, porém, Valadares Filho et al. (2006) recomendaram, a partir de dados de pesquisas realizadas no Brasil, a utilização de $120 \mathrm{~g} \mathrm{~kg}^{-1}$ de PBmic NDT como referência para eficiência de síntese microbiana em condições tropicais, inferior ao de $130 \mathrm{~g} \mathrm{~kg}^{-1}$ de PBmic NDT sugerido pelo NRC (2001). No presente estudo, a síntese da proteína microbiana, apesentou efeito quadrático, mas não afetou a eficiência microbiana $\mathrm{g} \mathrm{kg}^{-1}$ PBmic de NDT, com valor inferior ao NRC (2001), mesmo para o tratamento sem inclusão da palma forrageira, o que justifica que a eficiência microbiana está relacionada, com a fibra da silagem de sorgo. Allen e Grant (2000), relatam que o tipo e a quantidade de carboidratos presentes no alimento afetam a fermentação e a eficiência microbiana.

De acordo com o NRC (1996), a proteína microbiana pode contribuir com 50,0 a $100,0 \%$ das exigências de proteína metabolizável requerida por bovinos de corte. Detmann et al. (2005) ressaltaram que fermentações extensas de carboidratos podem ocorrer, mas resultam em baixo crescimento microbiano caso os compostos nitrogenados sejam fornecidos de forma inadequada. Em situações de elevada participação do nitrogênio não proteico sobre a proteína bruta da dieta basal, com limitação da fração proteica degradada no rúmen de natureza orgânica (aminoácidos e peptídeos), o desempenho animal pode ser comprometido.

\section{Conclusões}

A inclusão da palma forrageira em substituição à silagem de sorgo e concentrado, na alimentação de novilhas leiteiras confinadas, nas proporções estudadas, não alterou a concentração de nitrogênio ureico no plasma, a excreção de creatinina, o volume urinário e a eficiência microbiana.

A síntese de nitrogênio e proteína microbiana decresceu com inclusão do teor de palma forrageira acima de $166,77 \mathrm{~g} \mathrm{~kg}^{-1}$ na dieta, relacionada ao aumento dos carboidratos não fibrosos.

A palma forrageira pode ser utilizada até o teor de $600 \mathrm{~g} \mathrm{~kg}^{-1}$ em substituição ao volumoso e concentrado sem afetar a eficiência microbiana.

\section{Referências}

ALLEN, D. M.; GRANT, R. J. Interactions between forage and wet corn gluten feed as sources of fiber in diets for lactating dairy cows. Journal of Dairy Science, Madison, v. 83, n. 2, p. 322-331, 2000.

BRODERICK, G. A.; CLAYTON, M. K. A statistical evaluation of animal and nutritional factors influencing concentrations of milk urea nitrogen. Journal of Dairy Science, Madison, v. 80, n. 11, p. 2964-2971, 1997.

BUTLER, W. R.; CHERNEY, D. J. R.; ELROD, C. C. Milk urea nitrogen (MUN) analysis: field trial results on conception rates and dietary inputs. In: CORNELL PROCEEDINGS CONFERENCE, 1., 1995, Ithaca. Proceedings... Ithaca: Cornell University, 1995. p. 8995.

CAVALCANTE, M. A. B.; PEREIRA, O. G.; VALADARES FILHO, S. C.; RIBEIRO, K. G.; PACHECO, L. B. B.; ARAUJO, D.; LEMOS, V. M. C. Níveis de proteína bruta em dietas para bovinos de corte: parâmetros ruminais, balanço de compostos nitrogenados e produção de proteína microbiana. Revista Brasileira de Zootecnia, Viçosa, MG, v. 35, n. 1, p. 203-210, 2006.

CHEN, X. B.; GOMES, M. J. Estimation of microbial protein supply to sheep and cattle based on urinary excretion of purine derivatives - an overview of technical details. International Feed Resources Unit. Aberdeen: Rowett Research Institute, 1992. 21 p.

CHEN, X. B.; MEJIA, A. T.; KYLE, D. J.; ORSKOV, E. R. Evaluation of the use of purine derivative: creatinine ratio in spot urine and plasma samples as an index of microbial protein supply in ruminants: studies in sheep. Journal Agricultural Science, Cambridge, v. 125, n. 1, p. 137-143, 1995.

CHIZZOTTI, M. L.; VALADARES FILHO, S. C.; VALADARES, R. F. D.; CHIZZOTTI, F. H. M.; CAMPOS, J. M. S.; MARCONDES, M. I.; FONSECA, M. A. Consumo, digestibilidade e excreção de uréia e derivados de purinas em novilhas de diferentes pesos. Revista Brasileira de Zootecnia, Viçosa, MG, v. 35, n. 4, p. 1813-1821, 2006. Suplemento.

CHIZZOTTI, M. L.; VALADARES FILHO, S. C.; VALADARES, R. F. D.; CHIZZOTTI, F. H. M.; 
MARCONDES, M. I.; FONSECA, M. A. Consumo, digestibilidade e excreção de uréia e derivados de purinas em vacas de diferentes níveis de produção de leite. Revista Brasileira de Zootecnia, Viçosa, MG, v. 36, n. 1, p. 138-146, 2007.

CHIZZOTTI, M. L.; VALADARES FILHO, S. C.; VALADARES, R. F. D.; MARTINS, F. H.; MARCONDES, M. I.; FONSECA, M. A.; PORTO, M. O.; PINA, D. S.; LEAL, T. L.; SILVA, J. M.; ARAUJO, A. M. Excreção de creatinina em novilhos e novilhas. In: REUNIÃO ANUAL DA SOCIEDADE BRASILEIRA DE ZOOTECNIA, 41., 2004, Campo Grande. Anais... Campo Grande: Sociedade Brasileira de Zootecnia, 2004. CD-ROM.

CRUZ, M. C. S.; VÉRAS, A. S. S. C.; FERREIRA, M. A.; BATISTA, A. M. V.; SANTOS, C. S.; COELHO, M. I. S. Balanço de nitrogênio e estimativas de perdas endógenas em vacas lactantes alimentadas com dietas contendo palma forrageira e teores crescentes de ureia $\mathrm{e}$ mandioca. Acta Scientiarum Animal Sciences, Maringá, v. 28, n. 1, p. 47-56, 2006.

DETMANN, E.; PAULINO, M. F.; VALADARES FILHO, S. C.; CECON, P. R.; ZERVOUDAKIS, J. T.; CABRAL, L. S.; GONÇALVES, L. C.; VALADARES, R. F. D. Níveis de proteína em suplementos para terminação de bovinos em pastejo durante o período de transição seca/águas: digestibilidade aparente e parâmetros do metabolismo ruminal e dos compostos nitrogenados. Revista Brasileira de Zootecnia, Viçosa, MG, v. 34, n. 4, p. 1380-1391, 2005.

FERREIRA, M. A.; SILVA, R. R.; RAMOS, A. O.; VÉRAS, A. S. C.; MELO, A. A. S.; GUIMARÃES, A. V. Síntese de proteína microbiana e concentrações de ureia em vacas alimentadas com dietas à base de palma forrageira e diferentes volumosos. Revista Brasileira de Zootecnia, Viçosa, MG, v. 38, n. 1, p. 159-165, 2009.

HALL, M. B. Challenges with non-fiber carbohydrate methods. Journal of Animal Science, Champaign, v. 81, n. 12, p. 3226-3232, 2003.

HARMEYER, J.; MARTENS, H. Aspects of urea metabolism with reference to the goat. Journal of Dairy Science, Madison, v. 63, n. 10, p. 1707-1728, 1980.

ÍTAVO, L. C. V.; VALADARES FILHO, S. C.; SILVA, F. F.; VALADARES, R. F. D.; LEÃO, M. I.; CECON, P. R.; FERREIRA ITAVO, C. C. B.; MORAES, E. H. B. K.; RENNÓ, L. N.; PAULINO, P. V. R. Produção microbiana e parâmetros ruminais de novilhos alimentados com dietas contendo vários níveis de concentrado. Revista Brasileira de Zootecnia, Viçosa, MG, v. 31, n. 3, p. 15531561, 2002. Suplemento.
LICITRA, G.; HERNANDEZ, T. M.; VAN SOEST, P. J. Standartization of procedures for nitrogen fractionation of ruminant feeds. Animal Feed Science and Technology, Amsterdam, v. 57, n. 4, p. 347-358, 1996.

MAGALHÃES, K. A.; VALADARES FILHO, S. C.; VALADARES, R. F. D.; PAIXÃO, M. L.; PINA, D. S.; PAULINO, P. V. R.; CHIZZOTTI, M. L.; MARCONDES, M. I.; ARAUJO, A. M.; PORTO, M. O. Produção de proteína microbiana, concentração plasmática de uréia e excreções de uréia em novilhos alimentados com diferentes níveis de uréia ou casca de algodão. Revista Brasileira de Zootecnia, Viçosa, MG, v. 34, n. 4, p. 14001407, 2005.

MERTENS, D. R. Gravimetric determination of amylasetreated neutral detergent fiber in feeds with refluxing beakers or crucibles: collaborative study. Journal of AOAC International, Rockville, v. 85, n. 6, p. 1217-1240, 2002.

NATIONAL RESEARCH COUNCIL - NRC. Nutrient requirements of the dairy cattle. $7^{\text {th }}$ ed. Washington, D. C., 2001. $381 \mathrm{p}$.

Nutrients requirements of beef cattle. $7^{\text {th }}$ ed. Washington, D. C., 1996. 244 p.

NOCEK, J. E.; RUSSELL, J. B. Protein and energy as an integrated system. Relation of ruminal protein and carbohydrates availability to microbial synthesis and milk production. Journal of Dairy Science, Madison, v. 71, n. 8, p. 2070-2107, 1988.

PESSOA, R. A. S.; LEÃO, M. I.; FERREIRA, M. A.; VALADARES FILHO, S. S.; VALADARES, R. F. D.; QUEIROZ, A. C. Balanço de compostos nitrogenados e produção de proteína microbiana em novilhas leiteiras alimentadas com palma forrageira, bagaço de canade-açúcar e ureia associados a diferentes suplementos. Revista Brasileira de Zootecnia, Viçosa, MG, v. 38, n. 5, p. 941-947, 2009.

PRESTON, R. L.; SCHNAKENBERG, D. D.; PFANDER, W. H. Protein utilization in ruminants. I. Blood urea nitrogen as affected by protein intake. Journal of Nutrition, Bethesda, v. 68, n. 3, p. 281-288, 1965.

RENNÓ, L. N.; VALADARES FILHO, S. C.; PAULINO, M. F.; LEÃO, M. I.; VALADARES, R. F. D.; RENNÓ, F. P.; PAIXÃO, M. L. Níveis de ureia na ração de novilhos de quatro grupos genéticos: parâmetros ruminais, ureia plasmática e excreções de ureia e creatinina. Revista Brasileira de Zootecnia, Viçosa, MG, v. 37, n. 3, p. 556562, 2008.

RENNÓ, L. N.; VALADARES, R. F. D.; VALADARES FILHO, S. C.; LEÃO, M. I.; SILVA, J. F. C.; CECON, P. 
R.; GONÇALVES, L. C.; DIAS, H. L. C.; LINHARES, R. S. Concentração plasmática de ureia e excreções de ureia e creatinina em novilhos. Revista Brasileira de Zootecnia, Viçosa, MG, v. 29, n. 4, p. 1235-1243, 2000.

SILVA, D. J.; QUEIROZ, A. C. Análise de alimentos: métodos químicos e biológicos. 3. ed. $4^{\text {a }}$ reimp. Viçosa, MG: UFV, 2009. 235 p.

SISTEMAS PARA ANÁLISES ESTATÍSTICAS SAEG. Versão 9. 0: Viçosa: Fundação Arthur Bernardes/ UFV, 2005.

VAGNONI, D. B.; BRODERICK, G. A.; CLAYTON, M. K.; HATFIELD, R. D. Excretion of purine derivatives by Holstein cows abomasally infused with incremental amounts of purines. Journal of Dairy Science, Madison, v. 80, n. 8, p. 1695-1702, 1997.

VALADARES FILHO, S. C.; MACHADO, P. A. S.; CHIZZOTTI, M. L.; AMARAL, H. F.; MAGALHÃES, K. A.; JÚNIOR ROCHA, V. R.; CAPELLE, E. R. CQBAL 3. 0. Tabelas brasileiras de composição de alimentos para bovinos. Viçosa: Gráfica Suprema, 2008. Disponível em: <http://www.ufv.br/cqbal>. Acesso em: 26 fev. 2013.

VALADARES FILHO, S. C.; PAULINO, P. V. R.; MAGALHÃES, K. A.; PAULINO, M. F.; DETMANN, E.; PINA, D. S.; AZEVEDO, J. A. G. Exigências nutricionais de zebuinos e tabelas de composição de alimentos - BR Corte. Viçosa, MG: Gráfica Suprema, 2006. $142 \mathrm{p}$.
VALADARES FILHO, S. C.; VALADARES, R. F. D. Recentes avanços em proteína na nutrição de vacas leiteiras. In: SIMPÓSIO INTERNACIONAL DE BOVINOCULTURA DE LEITE, SINLEITE, 2., 2001, Lavras. Anais... Lavras: Universidade Federal de Lavras, 2001. p. 228-243.

VALADARES, R. F. D.; BRODERICK, G. A.; VALADARES FILHO, S. C.; CLAYTON, M. K. Effect of replacing alfalfa with high moisture corn on ruminal protein synthesis estimated from excretion of total purine derivatives. Journal of Dairy Science, Madison, v. 8, n. 12, p. 2686-2696, 1999.

VALADARES, R. F. D.; GONÇALVES, L. C.; RODRIGUEZ, N. M.; VALADARES FILHO, S. C.; SAMPAIO, I. B. M. Níveis de proteína em dietas de bovinos. 4. Concentrações de amônia ruminal e ureia plasmática e excreções de ureia e creatinina. Revista Brasileira de Zootecnia, Viçosa, MG, v. 26, n. 6, p. 12701278, 1997.

VAN SOEST, P. J. Nutritional ecology of the ruminant. 2. ed. Ithaca: Cornell, 1994. 476 p.

VERBIC, J.; CHEN, X. B.; MACLEOD, N.A.; ØRSKOV, E. R. Excretion of purine derivatives by ruminants. Effect of microbial nucleic acid infusion on purine derivative excretion by steers. Journal of Agricultural Science, Cambridge, v. 114, n. 3, p. 243-248, 1990. 